\title{
Strong convergence of a general algorithm for nonexpansive mappings in Banach spaces
}

Shuang Wang*

\author{
"Correspondence: \\ wangshuang19841119@163.com \\ School of Mathematical Sciences, \\ Yancheng Teachers University, \\ Yancheng, Jiangsu 224051, \\ PR China
}

\begin{abstract}
In this work, we consider a general algorithm for a countable family of nonexpansive mappings in Banach spaces. We proved that the proposed algorithm converges strongly to a common fixed point of a countable family of nonexpansive mappings which solves uniquely the corresponding variational inequality. It is worth pointing out that our proofs contain some new techniques. Our results improve and extend the corresponding ones announced by many others.
\end{abstract}

MSC: $47 \mathrm{H} 05 ; 47 \mathrm{H} 09 ; 47 \mathrm{H} 10$

Keywords: strong convergence; variational inequality; fixed points; $k$-Lipschitzian; $\eta$-strongly accretive; Banach space

\section{Introduction}

Let $X$ be a real Banach space and let $C$ be a nonempty closed convex subset of $X$. Recall that a mapping $T: C \rightarrow C$ is said to be nonexpansive if $\|T x-T y\| \leq\|x-y\|, \forall x, y \in C$. We denote by $\operatorname{Fix}(T)$ the set of fixed points of $T$.

In 2009, Yao et al. [1] considered the following algorithm in a Hilbert space. For an arbitrary point $x_{0} \in C$,

$$
\left\{\begin{array}{l}
y_{n}=P_{C}\left[\left(1-\alpha_{n}\right) x_{n}\right], \\
x_{n+1}=\left(1-\beta_{n}\right) x_{n}+\beta_{n} T y_{n}, \quad n \geq 0 .
\end{array}\right.
$$

They proved if $\left\{\alpha_{n}\right\}$ and $\left\{\beta_{n}\right\}$ satisfy appropriate conditions, the $\left\{x_{n}\right\}$ defined by (1.1) converges strongly to a fixed point of $T$.

Recently, motivated and inspired by the above results, Wang and $\mathrm{Hu}$ [2] introduced the following algorithm in a Hilbert space. For an arbitrary point $x_{1} \in C$,

$$
\left\{\begin{array}{l}
y_{n}=P_{C}\left[\left(I-\alpha_{n} F\right) x_{n}\right], \\
x_{n+1}=\left(1-\beta_{n}\right) x_{n}+\beta_{n} T_{n} y_{n}, \quad n \geq 1,
\end{array}\right.
$$

where $P_{C}: X \rightarrow C$ is a metric projection, $F: C \rightarrow X$ is a $\beta$-Lipschitzian and $\eta$-strongly monotone operators. They proved that the proposed algorithm converges strongly to $x^{*} \in$ $\bigcap_{n=1}^{\infty} \operatorname{Fix}\left(T_{n}\right)$, which solves the variational inequality $\left\langle F x^{\prime \prime}, x^{\prime \prime}-u\right\rangle \leq 0, u \in \bigcap_{n=1}^{\infty} \operatorname{Fix}\left(T_{n}\right)$. 
On the other hand, Aoyama et al. [3] considered the following algorithm in a uniformly convex and 2-uniformly smooth Banach space. For $x_{1}=x \in C$,

$$
x_{n+1}=\alpha_{n} x_{n}+\left(1-\alpha_{n}\right) Q_{C}\left(x_{n}-\lambda_{n} A x_{n}\right),
$$

where $Q_{C}: X \rightarrow C$ is a sunny nonexpansive retraction, and $A$ is a $\beta$-Lipschitzian and $\eta$-inverse strongly accretive operator. They proved that $\left\{x_{n}\right\}$ generated by (1.3) converges weakly to a unique element $z$ of $S(C, A)$, where $S(C, A)=\{u \in C:\langle A u, j(v-u)\rangle \geq 0, \forall v \in C\}$.

The results of Yao et al. [1] and Wang and $\mathrm{Hu}$ [2] both are obtained when the underlying space is a Hilbert space. Meanwhile, Aoyama et al. [3] just obtained a weak convergence theorem for strongly accretive and Lipschitzian operators. So, the above results bring us the following natural question.

Question 1.1 How to extend the results of Yao et al. [1] and Wang and $\mathrm{Hu}$ [2] to the more general uniformly convex and 2-uniformly smooth Banach space?

In this work, motivated and inspired by the above results, we introduce a general algorithm (3.1) (defined below) for a countable family of nonexpansive mappings in a uniformly convex and 2-uniformly smooth Banach space. We prove that the sequence $\left\{x_{n}\right\}$ defined by (3.1) converges strongly to $x^{*} \in \bigcap_{n=1}^{\infty} \operatorname{Fix}\left(T_{n}\right)$, which solves uniquely the variational inequality $\left\langle F x^{*}, j\left(x^{*}-u\right)\right\rangle \leq 0, u \in \bigcap_{n=1}^{\infty} \operatorname{Fix}\left(T_{n}\right)$. Furthermore, we provide an affirmative answer to Question 1.1. It is worth pointing out that our proofs contain some new techniques.

\section{Preliminaries}

Let $X$ be a real Banach space with the norm $\|\cdot\|$ and let $X^{*}$ be its dual space. The value of $f \in X^{*}$ and $x \in X$ will be denoted by $\langle x, f\rangle$. For the sequence $\left\{x_{n}\right\}$ in $X$, we write $x_{n} \rightarrow x$ to indicate that the sequence $\left\{x_{n}\right\}$ converges weakly to $x . x_{n} \rightarrow x$ means that $\left\{x_{n}\right\}$ converges strongly to $x$.

Let $\eta>0$. A mapping $F$ from $C$ into $X$ is said to be $\eta$-strongly accretive if there exists $j(x-y) \in J(x-y)$ such that

$$
\langle F x-F y, j(x-y)\rangle \geq \eta\|x-y\|^{2}
$$

for all $x, y \in C$. A mapping $F$ from $C$ into $X$ is said to be $\beta$-Lipschitzian if, for $\beta>0$,

$$
\|F x-F y\| \leq \beta\|x-y\|
$$

for all $x, y \in C$. It is well known that the $\eta$-strongly accretive operators are the extension of the $\eta$-strongly monotone operators from Hilbert spaces to Banach spaces.

Let $U=\{x \in X:\|x\|=1\}$. A Banach space $X$ is said to be uniformly convex if, for each $\epsilon \in(0,2]$, there exists $\delta>0$ such that, for any $x, y \in U$,

$$
\|x-y\| \geq \epsilon \quad \text { implies } \quad\left\|\frac{x+y}{2}\right\| \leq 1-\delta
$$


It is known that a uniformly convex Banach space is reflexive and strictly convex. A Banach space $X$ is said to be smooth if the limit

$$
\lim _{t \rightarrow 0} \frac{\|x+t y\|-\|x\|}{t}
$$

exists for all $x, y \in U$. It is said to be uniformly smooth if the limit (2.1) is attained uniformly for $x, y \in U$. Also, we define a function $\rho:[0, \infty) \rightarrow[0, \infty)$ called the modulus of smoothness of $X$ as follows:

$$
\rho(\tau)=\sup \left\{\frac{1}{2}(\|x+y\|+\|x-y\|)-1: x, y \in X,\|x\|=1,\|y\|=\tau\right\} .
$$

It is known that $X$ is uniformly smooth if and only if $\lim _{\tau \rightarrow 0} \rho(\tau) / \tau=0$. Let $q$ be a fixed real number with $1<q \leq 2$. Then a Banach space $X$ is said to be $q$-uniformly smooth if there exists a constant $c>0$ such that $\rho(\tau) \leq c \tau^{q}$ for all $\tau>0$. One should note that no Banach space is $q$-uniformly smooth for $q>2$; see [4] for more details. So, in this paper, we focus on a 2-uniformly smooth Banach space. It is well known that Hilbert spaces and Lebesgue $L^{p}(p \geq 2)$ spaces are uniformly convex and 2-uniformly smooth.

In order to prove our main results, we need the following lemmas.

Lemma 2.1 ([5]) Let $q$ be a given real number with $1<q \leq 2$ and let $X$ be a $q$-uniformly smooth Banach space. Then

$$
\|x+y\|^{q} \leq\|x\|^{q}+q\left\langle y, J_{q}(x)\right\rangle+2\|K y\|^{q}
$$

for all $x, y \in X$, where $K$ is the q-uniformly smooth constant of $X$ and $J_{q}$ is the generalized duality mapping from $X$ into $2^{X^{*}}$ defined by

$$
J_{q}(x)=\left\{f \in X^{*}:\langle x, f\rangle=\|x\|^{q},\|f\|=\|x\|^{q-1}\right\}
$$

for all $x \in X$.

Let $D$ be a subset of $C$ and let $Q$ be a mapping of $C$ into $D$. Then $Q$ is said to be sunny if

$$
Q[Q(x)+t(x-Q(x))]=Q(x)
$$

whenever $Q(x)+t(x-Q(x)) \in C$ for $x \in C$ and $t \geq 0$. A mapping $Q$ of $C$ into itself is called a retraction if $Q^{2}=Q$. If a mapping $Q$ of $C$ into itself is a retraction, then $Q(z)=z$ for every $z \in R(Q)$, where $R(Q)$ is the range of $Q$. A subset $D$ of $C$ is called a sunny nonexpansive retract of $C$ if there exists a sunny nonexpansive retraction from $C$ onto $D$. The following lemma concerns the sunny nonexpansive retraction.

Lemma 2.2 ([6]) Let $C$ be a closed convex subset of a smooth Banach space $X$, let $D$ be a nonempty subset of $C$ and $Q$ be a retraction from $C$ onto $D$. Then $Q$ is sunny and nonexpansive if and only if

$$
\langle u-Q(u), j(y-Q(u))\rangle \leq 0
$$

for all $u \in C$ and $y \in D$. 
Remark 2.3 It is well known that if $X$ is a Hilbert space, then a sunny nonexpansive retraction $Q_{C}: X \rightarrow C$ is coincident with the metric projection $P_{C}$ from $X$ onto $C$.

Lemma 2.4 ([7]) Let C be a nonempty bounded closed convex subset of a uniformly convex Banach space $X$ and let $T$ be a nonexpansive mapping of $C$ into itself. If $\left\{x_{n}\right\}$ is a sequence of $C$ such that $x_{n} \rightarrow x$ and $x_{n}-T x_{n} \rightarrow 0$, then $x$ is a fixed point of $T$.

Lemma $2.5([8,9])$ Let $\left\{s_{n}\right\}$ be a sequence of non-negative real numbers satisfying

$$
s_{n+1} \leq\left(1-\lambda_{n}\right) s_{n}+\lambda_{n} \delta_{n}+\gamma_{n}, \quad n \geq 0,
$$

where $\left\{\lambda_{n}\right\},\left\{\delta_{n}\right\}$ and $\left\{\gamma_{n}\right\}$ satisfy the following conditions: (i) $\left\{\lambda_{n}\right\} \subset[0,1]$ and $\sum_{n=0}^{\infty} \lambda_{n}=$ $\infty$, (ii) $\limsup _{n \rightarrow \infty} \delta_{n} \leq 0$ or $\sum_{n=0}^{\infty} \lambda_{n} \delta_{n}<\infty$, (iii) $\gamma_{n} \geq 0(n \geq 0), \sum_{n=0}^{\infty} \gamma_{n}<\infty$. Then $\lim _{n \rightarrow \infty} s_{n}=0$.

Lemma 2.6 ([10, Lemma 3.2]) Let $C$ be a nonempty closed convex subset of a Banach space E. Suppose that

$$
\sum_{n=1}^{\infty} \sup \left\{\left\|T_{n+1} z-T_{n} z\right\|: z \in C\right\}<\infty
$$

Then, for each $y \in C,\left\{T_{n} y\right\}$ converges strongly to some point of $C$. Moreover, let $T$ be a mapping of $C$ into itself defined by $T y=\lim _{n \rightarrow \infty} T_{n} y$ for all $y \in C$. Then $\lim _{n \rightarrow \infty} \sup \{\| T z-$ $\left.T_{n} z \|: z \in C\right\}=0$.

Furthermore, we need the following extension of Lemma 2.5 in Wang and Hu [2] in a 2-uniformly smooth Banach space.

Lemma 2.7 Let C be a nonemptyclosed convex subset of a real 2-uniformly smooth Banach space $X$. Let $F: C \rightarrow X$ be a $\beta$-Lipschitzian and $\eta$-strongly accretive operator with $0<\eta \leq$ $\sqrt{2} \beta K$ and $0<t<\eta / 2 \beta^{2} K^{2}$. Then $S=(I-t F): C \rightarrow X$ is a contraction with a contraction coefficient $\tau_{t}=\sqrt{1-2 t\left(\eta-t \beta^{2} K^{2}\right)}$.

Proof Using Lemma 2.1, we have

$$
\begin{aligned}
\|S x-S y\|^{2} & =\|(x-y)-t(F x-F y)\|^{2} \\
& \leq\|x-y\|^{2}-2 t\langle F x-F y, j(x-y)\rangle+2 t^{2} K^{2}\|F x-F y\|^{2} \\
& \leq\|x-y\|^{2}-2 t \eta\|x-y\|^{2}+2 t^{2} \beta^{2} K^{2}\|x-y\|^{2} \\
& =\left[1-2 t\left(\eta-t \beta^{2} K^{2}\right)\right]\|x-y\|^{2}
\end{aligned}
$$

for all $x, y \in C$. From $0<\eta \leq \sqrt{2} \beta K$ and $0<t<\eta / 2 \beta^{2} K^{2}$, we have

$$
\|S x-S y\| \leq \tau_{t}\|x-y\|
$$

where $\tau_{t}=\sqrt{1-2 t\left(\eta-t \beta^{2} K^{2}\right)} \in(0,1)$. Hence, $S$ is a contraction with a contraction coefficient $\tau_{t}$. 


\section{Main results}

We now state and prove the main results of this paper.

Theorem 3.1 Let $C$ be a nonempty closed convex subset and sunny nonexpansive retract of a uniformly convex and 2-uniformly smooth Banach space $X$. Let $F: C \rightarrow X$ be a $\beta$-Lipschitzian and $\eta$-strongly accretive operator with $0<\eta \leq \sqrt{2} \beta K$. Let $\left\{T_{n}\right\}$ be a sequence of nonexpansive mappings from $C$ into itself such that $\sum_{n=1}^{\infty} \sup \left\{\left\|T_{n+1} z-T_{n} z\right\|: z \in\right.$ $B\}<\infty$ for each bounded subset $B$ of $C$. Suppose, in addition, that $\operatorname{Fix}(T)=\bigcap_{n=1}^{\infty} \operatorname{Fix}\left(T_{n}\right) \neq$ $\emptyset$, where $T: C \rightarrow C$ is the nonexpansive mapping defined by $T z=\lim _{n \rightarrow \infty} T_{n} z$. Let $Q_{C}$ be a sunny nonexpansive retraction from $X$ onto $C$. Let $\left\{\alpha_{n}\right\}$ and $\left\{\beta_{n}\right\}$ be two real sequences in $(0,1)$ and satisfy the following conditions:

(A1) $\lim _{n \rightarrow \infty} \alpha_{n}=0$ and $\sum_{n=1}^{\infty} \alpha_{n}=\infty$;

(A2) $0<\liminf _{n \rightarrow \infty} \beta_{n} \leq \limsup _{n \rightarrow \infty} \beta_{n}<1$.

For given $x_{1} \in C$ arbitrarily, let the sequence $\left\{x_{n}\right\}$ be generated by

$$
\left\{\begin{array}{l}
y_{n}=Q_{C}\left(I-\alpha_{n} F\right) x_{n}, \\
x_{n+1}=\left(1-\beta_{n}\right) x_{n}+\beta_{n} T_{n} y_{n}, \quad n \geq 1 .
\end{array}\right.
$$

Then the sequence $\left\{x_{n}\right\}$ strongly converges to a point $x^{*} \in \bigcap_{n=1}^{\infty} \operatorname{Fix}\left(T_{n}\right)$ which solves uniquely the variational inequality

$$
\left\langle F x^{*}, j\left(x^{*}-u\right)\right\rangle \leq 0, \quad u \in \bigcap_{n=1}^{\infty} \operatorname{Fix}\left(T_{n}\right)
$$

Proof We proceed with the following steps.

Step 1. We claim that $\left\{x_{n}\right\}$ is bounded. From $\lim _{n \rightarrow \infty} \alpha_{n}=0$, we may assume, without loss of generality, that $0<\alpha_{n} \leq \eta / 2 \beta^{2} K^{2}-\epsilon$ for all $n$, where $\epsilon$ is an arbitrarily small positive number. In fact, let $u \in \bigcap_{n=1}^{\infty} \operatorname{Fix}\left(T_{n}\right)$, from (3.1) and using Lemma 2.7, we have

$$
\begin{aligned}
\left\|y_{n}-u\right\| & =\left\|Q_{C}\left(I-\alpha_{n} F\right) x_{n}-Q_{C} u\right\| \\
& \leq\left\|\left(I-\alpha_{n} F\right) x_{n}-\left(I-\alpha_{n} F\right) u-\alpha_{n} F u\right\| \\
& \leq \tau_{\alpha_{n}}\left\|x_{n}-u\right\|+\alpha_{n}\|F u\|,
\end{aligned}
$$

where $\tau_{\alpha_{n}}=\sqrt{1-2 \alpha_{n}\left(\eta-\alpha_{n} \beta^{2} K^{2}\right)} \in(0,1)$. Then from (3.1) and (3.2), we obtain

$$
\begin{aligned}
\left\|x_{n+1}-u\right\| & =\left\|\left(1-\beta_{n}\right)\left(x_{n}-u\right)+\beta_{n}\left(T_{n} y_{n}-u\right)\right\| \\
& \leq\left(1-\beta_{n}\right)\left\|x_{n}-u\right\|+\beta_{n}\left\|y_{n}-u\right\| \\
& \leq\left(1-\beta_{n}\right)\left\|x_{n}-u\right\|+\beta_{n}\left(\tau_{\alpha_{n}}\left\|x_{n}-u\right\|+\alpha_{n}\|F u\|\right) \\
& \leq\left[1-\beta_{n}\left(1-\tau_{\alpha_{n}}\right)\right]\left\|x_{n}-u\right\|+\beta_{n} \alpha_{n}\|F u\| \\
& \leq \max \left\{\left\|x_{n}-u\right\|, \frac{\alpha_{n}\|F u\|}{1-\tau_{\alpha_{n}}}\right\} .
\end{aligned}
$$

Observe that

$$
\lim _{n \rightarrow \infty} \frac{\alpha_{n}}{1-\tau_{\alpha_{n}}}=\lim _{t \rightarrow 0^{+}} \frac{t}{1-\tau_{t}}=\frac{1}{\eta} .
$$


Thus, we have $\alpha_{n} /\left(1-\tau_{\alpha_{n}}\right)$ is continuous, $\forall \alpha_{n} \in\left[0, \eta / 2 \beta^{2} K^{2}-\epsilon\right]$. Therefore, we obtain $M_{1}=\sup \left\{\frac{\alpha_{n}}{1-\tau_{\alpha_{n}}}: 0<\alpha_{n} \leq \frac{\eta}{2 \beta^{2} K^{2}}-\epsilon\right\}<+\infty$. By induction, we have

$$
\left\|x_{n}-u\right\| \leq \max \left\{\left\|x_{1}-u\right\|, M_{1}\|F u\|\right\} .
$$

Therefore, $\left\{x_{n}\right\}$ is bounded. We also obtain that $\left\{y_{n}\right\},\left\{T_{n} y_{n}\right\}$ and $\left\{F x_{n}\right\}$ are bounded. Without loss of generality, we may assume that $\left\{x_{n}\right\},\left\{y_{n}\right\},\left\{T_{n} y_{n}\right\}$ and $\left\{F x_{n}\right\} \subset B$, where $B$ is a bounded set of $C$.

Step 2. We claim that $\lim _{n \rightarrow \infty}\left\|y_{n}-T_{n} y_{n}\right\|=0$. Using the same method as in Step 2 of the proof in [2, Theorem 3.5], we have $\lim _{n \rightarrow \infty}\left\|x_{n+1}-x_{n}\right\|=0$. Observe that

$$
\begin{aligned}
\left\|y_{n}-T_{n} y_{n}\right\| & \leq\left\|y_{n}-x_{n}\right\|+\left\|x_{n}-x_{n+1}\right\|+\left\|x_{n+1}-T_{n} y_{n}\right\| \\
& \leq \alpha_{n}\left\|F x_{n}\right\|+\left\|x_{n}-x_{n+1}\right\|+\left(1-\beta_{n}\right)\left\|x_{n}-T_{n} y_{n}\right\| \\
& \leq \alpha_{n}\left\|F x_{n}\right\|+\left\|x_{n}-x_{n+1}\right\|+\left(1-\beta_{n}\right)\left(\left\|x_{n}-y_{n}\right\|+\left\|y_{n}-T_{n} y_{n}\right\|\right) \\
& \leq 2 \alpha_{n}\left\|F x_{n}\right\|+\left\|x_{n}-x_{n+1}\right\|+\left(1-\beta_{n}\right)\left\|y_{n}-T_{n} y_{n}\right\|,
\end{aligned}
$$

that is,

$$
\left\|y_{n}-T_{n} y_{n}\right\| \leq \frac{1}{\beta_{n}}\left(2 \alpha_{n}\left\|F x_{n}\right\|+\left\|x_{n+1}-x_{n}\right\|\right) \rightarrow 0 \quad(n \rightarrow \infty) .
$$

Step 3. We claim that $\lim _{n \rightarrow \infty}\left\|y_{n}-T y_{n}\right\|=0$. Observe that

$$
\begin{aligned}
\left\|y_{n}-T y_{n}\right\| & \leq\left\|y_{n}-T_{n} y_{n}\right\|+\left\|T_{n} y_{n}-T y_{n}\right\| \\
& \leq\left\|y_{n}-T_{n} y_{n}\right\|+\sup \left\{\left\|T_{n} z-T z\right\|: z \in B\right\} .
\end{aligned}
$$

Hence, from Step 2 and using Lemma 2.6, we have

$$
\lim _{n \rightarrow \infty}\left\|y_{n}-T y_{n}\right\|=0 .
$$

Step 4. We claim that $\lim \sup _{n \rightarrow \infty}\left\langle F x^{\prime \prime}, j\left(x^{\prime \prime}-y_{n}\right)\right\rangle \leq 0$, where $x^{\prime \prime}=\lim _{t \rightarrow 0^{+}} x_{t}$ and $x_{t}$ is defined by $x_{t}=Q_{C}(I-t F) T x_{t}$.

From $t \rightarrow 0^{+}$, we may assume, without loss of generality, that $t \in\left(0, \eta / 2 \beta^{2} K^{2}-\epsilon\right]$. Using Lemma 2.7, it is easy to see that $Q_{C}(I-t F) T$ is a contraction. Thus, $x_{t}$ is well defined. Next, we show that $x^{*}$ is well defined. Let $u \in \operatorname{Fix}(T)$, using Lemma 2.7, we have

$$
\begin{aligned}
\left\|x_{t}-u\right\| & =\left\|Q_{C}(I-t F) T x_{t}-Q_{C} T u\right\| \\
& \leq\left\|(I-t F) T x_{t}-(I-t F) T u-t F T u\right\| \\
& \leq\left\|(I-t F) T x_{t}-(I-t F) T u\right\|+t\|F u\| \\
& \leq \tau_{t}\left\|x_{t}-u\right\|+t\|F u\|,
\end{aligned}
$$

that is,

$$
\left\|x_{t}-u\right\| \leq \frac{t}{1-\tau_{t}}\|F u\| \leq M_{1}\|F u\| .
$$


Thus, we have $\left\{x_{t}\right\}$ is bounded and so is $\left\{F T x_{t}\right\}$. On the other hand, we have

$$
\begin{aligned}
\left\|x_{t}-T x_{t}\right\| & =\left\|Q_{C}(I-t F) T x_{t}-Q_{C} T x_{t}\right\| \\
& \leq\left\|(I-t F) T x_{t}-T x_{t}\right\|=t\left\|F T x_{t}\right\| \rightarrow 0 \quad\left(t \rightarrow 0^{+}\right) .
\end{aligned}
$$

Assume that $\left\{t_{n}\right\} \in\left(0, \eta / 2 \beta^{2} K^{2}-\epsilon\right]$ such that $t_{n} \rightarrow 0^{+}$as $n \rightarrow \infty$. Put $\widetilde{x_{n}}:=x_{t_{n}}$. It follows from (3.3) that $\left\|\widetilde{x_{n}}-T \tilde{x_{n}}\right\| \rightarrow 0(n \rightarrow \infty)$. Since $\left\{x_{t}\right\}$ is bounded, without loss of generality, we may assume that $\widetilde{x_{n}} \rightarrow x^{*}$. We can use Lemma 2.4 to get $x^{*} \in \operatorname{Fix}(T)$. Therefore, using Lemma 2.2 and Lemma 2.7, we have

$$
\begin{aligned}
\left\|x_{t}-x^{*}\right\|^{2} & =\left\langle x_{t}-x^{*}, j\left(x_{t}-x^{*}\right)\right\rangle \\
& =\left\langle x_{t}-(I-t F) T x_{t}, j\left(x_{t}-x^{*}\right)\right\rangle+\left\langle(I-t F) T x_{t}-x^{*}, j\left(x_{t}-x^{*}\right)\right\rangle \\
& \leq\left\langle(I-t F) T x_{t}-x^{*}, j\left(x_{t}-x^{*}\right)\right\rangle \\
& \leq\left\langle(I-t F) T x_{t}-(I-t F) T x^{*}, j\left(x_{t}-x^{*}\right)\right\rangle+t\left\langle F x^{*}, j\left(x^{*}-x_{t}\right)\right\rangle \\
& \leq \tau_{t}\left\|x_{t}-x^{*}\right\|^{2}+t\left\langle F x^{*}, j\left(x^{*}-x_{t}\right)\right\rangle,
\end{aligned}
$$

that is,

$$
\left\|x_{t}-x^{*}\right\|^{2} \leq \frac{t}{1-\tau_{t}}\left\langle F x^{*}, j\left(x^{*}-x_{t}\right)\right\rangle \leq M_{1}\left\langle F x^{*}, j\left(x^{*}-x_{t}\right)\right\rangle
$$

In particular,

$$
\left\|\widetilde{x_{n}}-x^{*}\right\|^{2} \leq M_{1}\left\langle F x^{*}, j\left(x^{*}-\tilde{x_{n}}\right)\right\rangle \text {. }
$$

Consequently, the weak convergence of $\left\{\tilde{x}_{n}\right\}$ to $x^{*}$ actually implies that $x_{n} \rightarrow x^{*}$. Therefore, $x^{*}=\lim _{t \rightarrow 0^{+}} x_{t}$ is well defined.

Since $y_{n}$ is bounded, there exists a subsequence $\left\{y_{n_{k}}\right\}$ of $\left\{y_{n}\right\}$ which converges weakly to $\omega$. From Step 3 and using Lemma 2.4, we have $\omega \in \operatorname{Fix}(T)$. Observe that

$$
\limsup _{n \rightarrow \infty}\left\langle F x^{*}, j\left(x^{*}-y_{n}\right)\right\rangle=\lim _{k \rightarrow \infty}\left\langle F x^{*}, j\left(x^{*}-y_{n_{k}}\right)\right\rangle=\left\langle F x^{*}, j\left(x^{*}-\omega\right)\right\rangle .
$$

On the other hand, we have

$$
\begin{aligned}
x_{t} & =Q_{C}(I-t F) T x_{t}-(I-t F) T x_{t}-(I-t F) x_{t}+(I-t F) T x_{t}+x_{t}-t F x_{t} \\
& \Rightarrow \quad F x_{t}=\frac{1}{t}\left[Q_{C}(I-t F) T x_{t}-(I-t F) T x_{t}-(I-t F) x_{t}+(I-t F) T x_{t}\right] .
\end{aligned}
$$

Therefore, for $\omega \in \operatorname{Fix}(T)$, we can use Lemma 2.2 to get

$$
\begin{aligned}
\left\langle F x_{t}, j\left(x_{t}-\omega\right)\right\rangle= & \frac{1}{t}\left\langle Q_{C}(I-t F) T x_{t}-(I-t F) T x_{t}, j\left(x_{t}-\omega\right)\right\rangle \\
& -\frac{1}{t}\left\langle(I-t F) x_{t}-(I-t F) T x_{t}, j\left(x_{t}-\omega\right)\right\rangle \\
\leq & -\frac{1}{t}\left\langle x_{t}-T x_{t}, j\left(x_{t}-\omega\right)\right\rangle+\left\langle F x_{t}-F T x_{t}, j\left(x_{t}-\omega\right)\right\rangle
\end{aligned}
$$




$$
\begin{aligned}
& \leq-\frac{1}{t}\left\langle(I-T) x_{t}-(I-T) \omega, j\left(x_{t}-\omega\right)\right\rangle+\beta\left\|x_{t}-T x_{t}\right\|\left\|x_{t}-\omega\right\| \\
& \leq \beta M_{2}\left\|x_{t}-T x_{t}\right\|,
\end{aligned}
$$

where $M_{2}=\sup \left\{\left\|x_{t}-\omega\right\|, t \in\left(0, \eta / 2 \beta^{2} K^{2}-\epsilon\right]\right\}$. Now replacing $t$ in (3.5) with $t_{n}$ and letting $n \rightarrow \infty$, we have

$$
\left\langle F x^{*}, j\left(x^{*}-\omega\right)\right\rangle \leq 0 .
$$

From (3.4) and (3.6), we obtain $\lim \sup _{n \rightarrow \infty}\left\langle F x^{*}, j\left(x^{*}-y_{n}\right)\right\rangle \leq 0$.

Step 5. We claim that $\left\{x_{n}\right\}$ converges strongly to $x^{*} \in \bigcap_{n=1}^{\infty} F\left(T_{n}\right)$. From (3.1) and using Lemma 2.2, we have

$$
\left\langle Q_{C}\left(I-\alpha_{n} F\right) x_{n}-\left(I-\alpha_{n} F\right) x_{n}, j\left(y_{n}-x^{*}\right)\right\rangle \leq 0 .
$$

Observe that

$$
\begin{aligned}
\left\|y_{n}-x^{*}\right\|^{2} & =\left\langle Q_{C}\left(I-\alpha_{n} F\right) x_{n}-x^{*}, j\left(y_{n}-x^{*}\right)\right\rangle \\
& =\left\langle Q_{C}\left(I-\alpha_{n} F\right) x_{n}-\left(I-\alpha_{n} F\right) x_{n}, j\left(y_{n}-x^{*}\right)\right\rangle+\left\langle\left(I-\alpha_{n} F\right) x_{n}-x^{*}, j\left(y_{n}-x^{*}\right)\right\rangle \\
& \leq\left\langle\left(I-\alpha_{n} F\right) x_{n}-x^{*}, j\left(y_{n}-x^{*}\right)\right\rangle \\
& \leq\left\langle\left(I-\alpha_{n} F\right) x_{n}-\left(I-\alpha_{n} F\right) x^{*}, j\left(y_{n}-x^{*}\right)\right\rangle+\alpha_{n}\left\langle F x^{*}, j\left(x^{*}-y_{n}\right)\right\rangle \\
& \leq\left\|\left(I-\alpha_{n} F\right) x_{n}-\left(I-\alpha_{n} F\right) x^{*}\right\|\left\|y_{n}-x^{*}\right\|+\alpha_{n}\left\langle F x^{*}, j\left(x^{*}-y_{n}\right)\right\rangle \\
& \leq \tau_{\alpha_{n}}\left\|x_{n}-x^{*}\right\|\left\|y_{n}-x^{*}\right\|+\alpha_{n}\left\langle F x^{*}, j\left(x^{*}-y_{n}\right)\right\rangle \\
& \leq \frac{\tau_{\alpha_{n}}^{2}}{2}\left\|x_{n}-x^{*}\right\|^{2}+\frac{1}{2}\left\|y_{n}-x^{*}\right\|^{2}+\alpha_{n}\left\langle F x^{*}, j\left(x^{*}-y_{n}\right)\right\rangle,
\end{aligned}
$$

that is,

$$
\left\|y_{n}-x^{*}\right\|^{2} \leq \tau_{\alpha_{n}}\left\|x_{n}-x^{*}\right\|^{2}+2 \alpha_{n}\left\langle F x^{*}, j\left(x^{*}-y_{n}\right)\right\rangle .
$$

By (3.1) and (3.7), we have

$$
\begin{aligned}
\left\|x_{n+1}-x^{*}\right\|^{2} & \leq\left(1-\beta_{n}\right)\left\|x_{n}-x^{*}\right\|^{2}+\beta_{n}\left\|T_{n} y_{n}-x^{*}\right\|^{2} \\
& \leq\left(1-\beta_{n}\right)\left\|x_{n}-x^{*}\right\|^{2}+\beta_{n}\left\|y_{n}-x^{*}\right\|^{2} \\
& \leq\left(1-\beta_{n}\right)\left\|x_{n}-x^{*}\right\|^{2}+\beta_{n}\left[\tau_{\alpha_{n}}\left\|x_{n}-x^{*}\right\|^{2}+2 \alpha_{n}\left\{F x^{*}, j\left(x^{*}-y_{n}\right)\right\rangle\right] \\
& \leq\left[1-\beta_{n}\left(1-\tau_{\alpha_{n}}\right)\right]\left\|x_{n}-x^{*}\right\|^{2}+2 M_{1} \beta_{n}\left(1-\tau_{\alpha_{n}}\right)\left\langle F x^{*}, j\left(x^{*}-y_{n}\right)\right\rangle \\
& =\left(1-\lambda_{n}\right)\left\|x_{n}-x^{*}\right\|^{2}+\lambda_{n} \delta_{n},
\end{aligned}
$$

where $\lambda_{n}=\beta_{n}\left(1-\tau_{\alpha_{n}}\right), \delta_{n}=2 M_{1}\left\langle F x^{*}, j\left(x^{*}-y_{n}\right)\right\rangle$. It is easy to see that $\sum_{n=1}^{\infty} \lambda_{n}=\infty$ and $\limsup _{n \rightarrow \infty} \delta_{n} \leq 0$. Hence, by Lemma 2.5, the sequence $\left\{x_{n}\right\}$ converges strongly to $x^{*} \in$ $\bigcap_{n=1}^{\infty} F\left(T_{n}\right)$.

Step 6. We claim that $x^{*}$ is a unique solution of the variational inequality $\left\langle F x^{*}, j\left(x^{*}-u\right)\right\rangle \leq$ $0, u \in \bigcap_{n=1}^{\infty} F\left(T_{n}\right)$. 
From Step 4, we have shown that $x^{*}$ is a solution of the variational inequality $\left\langle F x^{*}, j\left(x^{*}-\right.\right.$ $u)\rangle \leq 0, u \in \bigcap_{n=1}^{\infty} F\left(T_{n}\right)$. Without loss of generality, we assume that $\tilde{x} \in \operatorname{Fix}(T)$ is also a solution of the variational inequality. Therefore, we have

$$
\left\langle F x^{*}, j\left(x^{*}-\tilde{x}\right)\right\rangle \leq 0 \text {, }
$$

and

$$
\left\langle F \tilde{x}, j\left(\tilde{x}-x^{*}\right)\right\rangle \leq 0
$$

Adding up (3.8) and (3.9), we get

$$
\left\langle F x^{*}-F \tilde{x}, j\left(x^{*}-\tilde{x}\right)\right\rangle \leq 0 .
$$

The strong accretivity of $F$ implies that $x^{*}=\tilde{x}$ and the uniqueness is proved.

Remark 3.2 Obviously, Theorem 3.1 extends the results of Yao et al. [1] and Wang and $\mathrm{Hu}[2]$ to the more general uniformly convex and 2-uniformly smooth Banach space.

\section{Competing interests}

The author declares that she has no competing interests.

\section{Acknowledgements}

The author thanks the editor and the referees for their useful comments and suggestions. This study was supported by the Natural Science Foundation of Yancheng Teachers University under Grant (12YCKL001) and UNSF of Jiangsu province, China (09KJD110005)

Received: 23 March 2012 Accepted: 7 November 2012 Published: 22 November 2012

\section{References}

1. Yao, YH, Liou, YC, Marino, G: Strong convergence of two iterative algorithms for nonexpansive mappings in Hilbert spaces. Fixed Point Theory Appl. 2009, Article ID 279058 (2009)

2. Wang, S, Hu, CS: Two new iterative methods for a countable family of nonexpansive mappings in Hilbert spaces. Fixed Point Theory Appl. 2010, Article ID 852030 (2010)

3. Aoyama, $\mathrm{K}$, liduka, $\mathrm{H}$, Takahashi, W: Weak convergence of an iterative sequence for accretive operators in Banach spaces. Fixed Point Theory Appl. 2006, Article ID 35390 (2006)

4. Takahashi, Y, Hashimoto, K, Kato, M: On sharp uniform convexity, smoothness, and strong type, cotype inequalities. J. Nonlinear Convex Anal. 3, 267-281 (2002)

5. Xu, HK: Inequalities in Banach spaces with applications. Nonlinear Anal. 16, 1127-1138 (1991)

6. Reich, S: Weak convergence theorems for nonexpansive mappings in Banach spaces. J. Math. Anal. Appl. 67, 274-276 (1979)

7. Geobel, K, Kirk, WA: Topics in Metric Fixed Point Theory. Cambridge Studies in Advanced Mathematics, vol. 28. Cambridge University Press, Cambridge (1990)

8. Liu, LS: Iterative processes with errors for nonlinear strongly accretive mappings in Banach spaces. J. Math. Anal. Appl. $194,114-125$ (1995)

9. Xu, HK: Iterative algorithms for nonlinear operators. J. Lond. Math. Soc. 66, 240-256 (2002)

10. Aoyama, K, Kimura, Y, Takahashi, W, Toyoda, M: Approximation of common fixed points of a countable family of nonexpansive mappings in a Banach space. Nonlinear Anal. 67, 2350-2360 (2007)

doi:10.1186/1687-1812-2012-207

Cite this article as: Wang: Strong convergence of a general algorithm for nonexpansive mappings in Banach spaces. Fixed Point Theory and Applications 2012 2012:207. 